http://dx.doi.org/10.30681/23588403v12i014961

\title{
REFLEXÕES SOBRE O ENSINO DA LITERATURA E INCENTIVO À LEITURA ATRAVÉS DA RELEITURA DE CLÁSSICOS EM QUADRINHOS
}

Data de recebimento: 14/11/2017

Aceite: 08/02/2018

\section{Amanda do Nascimento dos Santos ALMEIDA (UERJ) ${ }^{1}$}

Resumo: O questionamento da importância do estudo de literatura na escola, agregando e fortalecendo a formação de leitores eficientes, assim como também para a vida. A metodologia utilizada foi a bibliográfica, trabalharemos com autores que versam questões no campo da educação e didática (LIBÂNEO, 2006) através de documentos oficiais - Parâmetros Curriculares Nacionais e Lei de Diretrizes e Bases - que regem o trabalho do professor em sala de aula, assim como a importância da literatura na sala de aula e na vida dos estudantes pelo do letramento literário (COSSON, 2006), leitura de clássicos (CALVINO, 2007), adaptações de clássicos (PERRONE-MOISÉS, 1990; STAM, 2006; EAGLETON, 1997), exemplos declássicos literários em quadrinhos - títulos brasileiros e estrangeiros que constam em diversas escolas públicas por aquisição própria ou através do Programa Nacional Biblioteca Escolar (PNBE), e finalmente uma reflexão a respeito da utilização pedagógica dos mesmos na formação e desenvolvimento de leitores.

Palavras-chave: Adaptações. Leitura. Quadrinhos. Formação de Leitores.

Abstract: The questioning of the importance of the study of literature in school, adding and strengthening the training of efficient readers, as well as for life. The methodology used was the bibliographical one, we will work with authors that deal with questions in the field of education and didactics (LIBÂNEO, 2006) through official documents - National Curricular Parameters and Law of Guidelines and Bases - that govern the work of the teacher in the classroom, As well as the importance of literature in the classroom and in the students' lives by the literary literacy (COSSON, 2006), reading classics (CALVINO, 2007), adaptations of classics (PERRONE-MOISÉS 1990; STAM 2006; EAGLETON, 1997), examples of literary classics in comics - Brazilian and foreign titles that appear in several public schools by own acquisition or through the National School Library Program (PNBE), and finally a reflection on the pedagogical use of them in the formation and development of readers.

Keywords: Adaptations. Reading. Comics.Training of Readers.

\section{Introdução}

Esse presente trabalho é fruto de alguns questionamentos e posicionamentos com os quais lidei nos últimos meses de graduação e durante a pós-graduação no curso de Gestão Escolar

\footnotetext{
${ }^{1}$ Graduada em Letras/Literatura (UERJ/FFP), Especialista em Educação Básica (UERJ/FFP) reside em Niterói, Brasil. Mestranda em Estudos de Literatura pela Universidade Federal Fluminense - UFF. E-mail: amandaalmeida.letras@gmail.com
} 
da Faculdade Formação de Professores - FFP/UERJ. Trata-se da importância e a funcionalidade da literatura na escola e fora dela.

O uso de textos literários dentro das salas de aula produz uma prática discursiva de leitura que expõe o leitor às diferentes redes discursivas de sentidos. Ou seja, é um texto que não está sendo utilizado como pretexto para este ou aquele exercício de gramática, como comumente verificamos em livros didáticos.

Todavia, enquanto o uso do texto não literário pode vir a mecanizar os processos de leitura, o texto literário estimula o aluno a viajar nas páginas de um livro buscando novas realidades, motivando-o a ler cada vez mais e melhor. Nessa perspectiva, a leitura é um ato complexo que precisa percorrer caminhos até que o leitor seja capaz de dominar a leitura e o entendimento de diferentes gêneros com plenitude.

Antes de adentrarmos a temática da leitura dos clássicos na escola, é importante compreendermos que a leitura como atividade de linguagem é uma prática social de alcance político, através dela, somos capazes de nos comunicarmos nas mais variadas situações e níveis de linguagem. E ainda, que ao promover a interação entre indivíduos, a leitura, compreendida não só como leitura da palavra, mas também como leitura de mundo, deve ser atividade constitutiva de sujeitos capazes de entender o mundo e nele atuar como cidadãos.

\section{1 - O Ensino Médio e o Ensino de Literatura - LDB e PCN's}

Este capítulo pretende apresentar orientações dos documentos oficiais quanto ao ensino de leitura e literatura, nos quais o trabalho do professor deve apoiar-se.

Em uma concepção de formação "do professor como intelectual crítico, profissional reflexivo, pesquisador e elaborador de conhecimentos, participante qualificado na organização e gestão da escola" (LIBÂNEO, 2003, p.66), entendemos a função fundamental da formação continuada desse profissional de educação, com vistas a subsidiar a reflexão sobre sua prática docente. É nessa perspectiva que surgiu a Lei de Diretrizes e Bases - LDB, Lei n 9.394/96, como forma de superar a ruptura entre a formação do professor e a do aluno, focando na adequação de práticas pedagógicas voltadas para a construção de competências e habilidades.

A Lei de Diretrizes e Bases orienta quanto ao currículo: os conteúdos, as metodologias e as formas de avaliação serão organizados de tal forma que ao final do ensino médio o educando 
demonstre: Domínio dos princípios científicos e tecnológicos que presidem a produção moderna e; Conhecimento das formas contemporâneas de linguagem.

As habilidades da língua portuguesa compreendem utilizar a palavra oralmente: ouvir e falar; e de utilizar a palavra escrita: ler e escrever. A seguir, trechos dos Parâmetros Curriculares Nacionais, quecomunicam-se com a proposta para a formação do leitor crítico: Nas orientações Curriculares para o Ensino Médio - Linguagens, Códigos e suas Tecnologias - Conhecimentos de língua Portuguesa, orienta-se que:

- As ações realizadas da disciplina Língua Portuguesa, no contexto do ensino médio, devem propiciar ao aluno o refinamento de habilidades de leitura e escrita, de fala e de escuta;

- O texto passa a ser visto como uma totalidade que só alcança esse status por um conjunto de construção de sentidos;

- Através das atividades de linguagem que o homem se constitui sujeito, só por intermédio delas é que tem condições de refletir sobre si mesmo;

- A língua é uma das formas de manifestação da linguagem, e um entre os sistemas semióticos construídos histórica e socialmente pelo homem;

- O papel da disciplina de língua portuguesa é o de possibilitar, por procedimentos sistemáticos, o desenvolvimento de ações de produção de linguagem em diferentes situações de interação;

- As práticas de linguagem a serem tomadas no espaço da escola não se restringem nem se filiam apenas aos padrões socioculturais hegemônicos;

- A escola que se pretende efetivamente inclusiva e aberta à diversidade não pode aterse ao letramento da letra, mas deve, isso sim, abrir-se para os multiletramentos, que, envolvendo uma enorme variação de mídias, constroem-se de forma multisemiótica e híbrida - por exemplo, nos hipertextosna imprensa ou na internet, por vídeos e filmes etc.

Os PCN's indicam como objetivos para o ensino fundamental que os alunos sejam capazes de:

- Posicionar-se de maneira crítica, responsável e construtiva nas diferentes situações sociais, utilizando o diálogo como forma de mediar conflitos e de tomar decisivas;

- Desenvolver o conhecimento ajustado de si mesmo e o sentimento de confiança em suas capacidades afetiva, física, cognitiva, ética, estética, de inter-relação pessoal e de 
inserção social, para agir com perseverança na busca de conhecimento e no exercício da cidadania;

- Utilizar diferentes linguagens: verbal, matemática, gráfica, plástica e corporal - como meio para produzir, expressar e comunicar suas ideias, interpretar e usufruir das produções culturais, em contextos públicos e privados, atendendo a diferentes intenções e situações de comunicação;

No processo de ensino-aprendizagem no ensino fundamental, espera-se que o estudante amplie o domínio ativo em diversas situações comunicativas o que desenvolverá sua capacidade de interação social no exercício da cidadania. Para isso, a escola deverá realizar atividades que possibilite ao aluno:

- Utilizar a linguagem na escuta e na produção de textos orais e na leitura e produção de textos escritos de modo a atender a múltiplas demandas sociais, responder a diferentes propósitos comunicativos e expressivos, e considerar as diferentes condições de produção de discurso;

- Utilizar a linguagem para estruturar a experiência e explicar a realidade, operando sobre as representações construídas em várias áreas de conhecimentos;

- Analisar criticamente os diferentes discursos, inclusive o próprio, desenvolvendo a capacidade de avaliação de textos;

- Usar os conhecimentos adquiridos por meio da prática de análise linguística para expandir sua capacidade de monitoração das possibilidades de uso da linguagem, ampliando a capacidade de análise crítica.

- A formação do leitor competente é um dos objetivos da escola, pois a leitura é o maior instrumento para a construção do conhecimento, portanto despertar o interesse pela mesma é o maior legado de um professor aos seus alunos.

\section{2 - Literaturae Ensino}

Enquanto o uso do texto não literário mecaniza os processos de leitura, o texto literário estimula o aluno a viajar nas páginas de um livro buscando novas realidades, motivando-o a ler cada vez mais e melhor.

Todo aluno deveria beneficiar-se dos efeitos do texto literário, no entanto há diversos fatores que envolvem desde a falta de interesse, à dificuldade de aquisição de obras literárias, 
passando ainda pelas possíveis falhas no processo educacional deste aluno que tende a repelir o ato de ler, e principalmente da leitura de clássicos famigeradamente tidos como "difíceis de ler".

A não adequação do texto à realidade e ao momento do aluno pode desencadear a falta de interesse na leitura em geral, principalmente quando o leitor ainda não está maduro o suficiente para compreender que na literatura há uma vasta gama de obras aptas para diferentes perfis.

As histórias em quadrinhos têm a capacidade de introduzir e desenvolver o mundo da leitura aos estudantes. Ao privilegiar o texto literário como mobilizador do estudo de língua portuguesa, toma-se como objeto a linguagem em ação, pois, na constante construção de sentidos por meio da palavra que se fundamenta pelo uso na vida social, o ser humano se torna capaz de conhecer a si mesmo, sua cultura e o mundo em que vive.

Se quisermos formar leitores capazes de experienciar toda força humanizadora da literatura, não basta apenas ler. (...) A simples leitura é apenas a forma mais determinada de leitura, porque esconde sob a aparência de simplicidade todas as implicações contidas no ato de ler e de ser letrado. (COSSON, Rildo. 2006)

RildoCosson, mestre em teoria da literatura, doutor em letras e pós-doutorado em educação, propõe o letramento literário constituído por quatro passos: motivação, introdução, leitura e interpretação.

A motivação, na proposta do autor seria a preparação do leitor para receber a obra, antecipação esta, cujos mecanismos passam despercebidos por nos parecerem naturais. A introdução, a apresentação do autor da obra e do livro físico também, enquanto que a leitura do texto literário é observada como uma experiência única, podendo ser individual ou em conjunto. E a interpretação, partindo do entretenimento dos enunciados que constituem as inferências, para chegar à construção do sentido do texto, dentro de um diálogo que envolve autor, leitor e comunidade.

Lendo e escrevendo, o aluno adquire a capacidade de desnudar as regras impostas pela norma padrão, que são importantes em vários aspectos, mas que sozinhas, não são capazes de estimular um indivíduo ao conhecimento. Dessa forma, este mesmo indivíduo descobre-se apropriado da linguagem e mais apto a utilizá-la. 


\title{
2 - Quadrinhos sim, porque não?
}

\begin{abstract}
A linguagem da crítica que lida com a adaptação de romances tem sido com frequência profundamente moralista, cheia de termos como infidelidade, traição, deformação, violação, vulgarização e profanação, cada acusação carregando sua carga específica de negatividade ultrajada. (STAM. 2000, p. 54).
\end{abstract}

As Histórias em Quadrinhos, ou simplesmente HQs, estão associadas à apresentação de texto e imagem que estabelecem uma ideia de complementaridade. Gênero muito popular entre crianças e adolescentes, as Histórias em Quadrinhos infelizmente ficaram, por muito tempo, relegadas ao injusto rótulo de "subgênero". Contudo, as HQs têm ganhado cada vez mais força, demonstrando que grandes histórias podem ser contadas por seus caminhos.

A primeira história em quadrinhos de que se tem notícias no mundo foi criada pelo artista americano Richard Outcault, em 1895. A linguagem das HQs, tal qual conhecemos hoje, com personagens fixos, ações fragmentadas e diálogos dispostos em balõezinhos de texto, foi inaugurada nos jornais sensacionalistas de Nova York com uma tirinha de Outcault, chamada The Yellow Kid, e fez tanto sucesso que acabou sendo disputada por jornais de renome. Claro que esse modelo utilizado por Outcault não surgiu do acaso, pois as histórias em quadrinhos mais antigas surgiram nos primórdios, basta lembrar que os homens das cavernas comunicavam-se através das pinturas rupestres, contando através de desenhos a saga diária de nossos ancestrais na luta pela sobrevivência.

As histórias em quadrinhos, HQs, gibis, revistinhas ou historietas no Brasil começaram a ser publicadas no século XIX, adotando um estilo satírico conhecido como cartuns, charges ou caricaturas e que depois se estabeleceria com as populares tiras. A edição de revistas próprias de histórias em quadrinhos no país começou no início do século XX.

As histórias em quadrinhos por sua vez, apropriam-se de recursos estilísticos que se transformam em uma linguagem própria de quadrinhos com ângulos, cores e perspectivas diferentes, com uma estruturação cronológica e causal das ações dos personagens nas histórias, fazendo os homens representarem a realidade a sua volta ou a realidade que querem criar. 
O uso do gênero das HQ é uma das formas de se produzir texto e de se incentivar e inserir as crianças no mundo da escrita pela ludicidade das gravuras, balões e fala das personagens e cores, o que pode ser um diferencial na formação deste leitor educação.

Esta informação é relevante, visto que o trabalho com o gênero deve ser iniciado e explorado como um gênero único e independente, a fim de que o estudante ao deparar-se com uma adaptação literária para quadrinhos, não acredite que a adaptação da obra em questão é necessariamente suficiente para que o seu aprendizado seja satisfatório, já que, o ato de existir uma adaptação de determinada obra não exclui a leitura do texto-fonte, mas a complementa.

\section{1 - ProgramaNacional Biblioteca Escolar - PNBE}

O texto literário constitui uma forma peculiar de representação e estilo em que predominam a força criativa da imaginação e a intenção estética. Não é mera fantasia que nada tem a ver com o que se entende por realidade, nem é puro exercício lúdico sobre as formas e sentidos da linguagem e da língua. (PCN's Língua Portuguesa, P. 26)

Quando o PNBE foi criado? Quais são seus objetivos? Qual o público-alvo? Que tipo de material é distribuído por este programa? Como ocorre sua execução? Como podem ser acessadas informações sobre a distribuição de obras no contexto do PNBE?

O Programa Nacional Biblioteca da Escola (PNBE), criado em 1997, tem por objetivo democratizar o acesso às fontes de informação e cultura, o fomento à leitura e à formação de alunos e professores leitores, o apoio à atualização e ao desenvolvimento profissional do professor, e ainda, viabilizar a diversificação das fontes de informação utilizadas nas escolas públicas brasileiras, possibilitando a professores e alunos o acesso a obras variadas, necessárias à formação de leitores e a aprendizagens diversificadas.

Para isso, são selecionados e distribuídos às escolas públicas do País acervos compostos dos seguintes gêneros literários: obras clássicas da literatura universal e brasileira, poema, conto, crônica, novela, teatro, texto da tradição popular; romance, memória, diário, biografia, relatos de experiências; livros de imagens e histórias em quadrinhos. 
Também são distribuídos outros materiais de apoio a professores e alunos, relativos ao currículo dos segmentos da educação básica, Obras de referência, de dois tipos como:

a) Temáticas: obras de referência, elaboradas com base no reconhecimento e na valorização da diversidade humana voltadas para estudantes e professores dos anos finais do ensino fundamental e do ensino médio. Essas obras devem contribuir para a formação de uma cultura cidadã e a afirmação de valores que se oponham a todo tipo de preconceito, discriminação e exclusão. Foram estabelecidos nove temas que contemplam as especificidades de populações que compõem a sociedade brasileira: indígena; quilombola; campo; educação de jovens e adultos; direitos humanos; sustentabilidade socioambiental; educação especial; relações étnico-raciais e juventude;

b) De apoio pedagógico: para ajudar os professores da educação básica regular e da educação de jovens e adultos na preparação dos planos de ensino e na aplicação de atividades em sala de aula com os alunos.

São alguns clássicosbrasileiros e estrangeiros adaptados em quadrinhos que podem ser utilizadas em sala de aula, e foram distribuídos peloPNBE:

- O Ateneu, Raul Pompeia, adaptado por Marcello Quintanilha (roteiro e arte) Distribuído pelo PNBE 2013;

- A Terceira Margem do Rio, conto de João Guimarães Rosa, adaptado por Maria Helena Rouanet (roteiro) e Thaís dos Anjos (arte) - distribuído pelo PNBE 2013;

- O Guarani, romance de José de Alencar, adaptado por Walter Vetillo - distribuído pelo PNBE 2011.

- O Alienista, conto de Machado de Assis, adaptado por Fábio Moon e Gabriel Bá obra distribuída pelo PNBE 2009;

- Sonho de Uma Noite de Verão, de Willian Shakespeare, adaptada por Lillo Parra e Wanderson de Souza - distribuída pelo PNBE 2013.

- Otelo, de Willian Shakespeare, adaptado por Jazz e Akira Sanoki - obra distribuída pelo PNBE 2013;

- Frankestein, de Mary Shelley, adaptado por Marion Mousse - obra distribuída pelo PNBE 2011;

- Frankestein, de Mary Shelley, adaptado por Taisa Borges - obra distribuída pelo PNBE 2013; 
- Robinson Crusoé, de Daniel Defoe, romance adaptado por Christophe Galthier distribuído pelo PNBE 2011.

Outras adaptações são parte da coleção Literatura Brasileira em Quadrinhos, da editora Escala Educacional e embora não tenham sido distribuídas pelo Programa Nacional BibliotromanecaEscolar, além de serem facilmente encontradas nas bibliotecas escolares ainda podem ser facilmente adquiridos pelo seu baixo custo, são elas:

- O Cortiço, de Aluísio de Azevedo, adaptado por Ronaldo Antonelli (Roteiro e adaptação), Francisco S. Vilachã (ilustração) e Fernando A. A. Rodrigues (cores);

- O Homem que Sabia Javanês, de Lima Barreto, adaptado por Jô Fevereiro (Roteiro, desenho e cores) e Sebastião Seabra (arte final);

- Um Músico Extraordinário, de Lima Barreto, adaptador por Francisco S. Vilachã (roteiro, desenhos e cor) e Fernando A. A. Rodrigues (cores);

- Miss Edith e seu Tio, conto de Lima Barreto, adaptador por Jô Fevereiro (roteiro, desenhos e arte final) e Jô \&CiçaSperl (cores);

- A Cartomante, de Machado de Assis, adaptador por Jô Fevereiro (Roteiro, desenho e arte final)e Jo Fevereiro e CiçaSperl (cores);

- O Enfermeiro, conto de Machado de Assis, adaptado por Francisco S. Vilachã (roteiro, desenhos e cores) e Fernando A. A. Rodrigues (cores);

- A Causa Secreta, conto de Machado de Assis, adaptado por Francisco S. Vilachã (roteiro, desenhos e cores) e Fernando A. A. Rodrigues (cores);

- Memórias de Um Sargento de Milícias, conto de Manuel Antonio de Almeida, adaptado por Indigo (roreiro), Bira Dantas (arte) e Maurilio DNA e Caio Freiras (cores);

- Casa Grande \&Senzala, romance de Gilberto Freyre, adaptado por Estêvão Pinto (roteiro), Ivan Wasth (ilustração) e Nouguchi (cores);

\section{3- Consideraçõesfinais}

“O que conta para nós na obra literária é a possibilidade de continuar a desfolhá-la como uma alcachofra infinita descobrindo dimensões de leitura sempre novas”. (CALVINO, 2007, p. 210).Um clássico é um livro que nunca terminou de dizer aquilo que tinha para dizer, e é nessa perspectiva que a releitura dá novos ares à obra da qual respira. Na releitura como 
inspiração, o escritor inspira o "ar" do ambiente para dentro, e ao expirá-lo, toma para si apenas o que caracteriza como de suma importância.

Dessa forma, na reescrita, nos oferece também a capacidade de encher os pulmões, respirar e refletir. Essa reflexão não necessariamente nos leva à satisfação, e no entanto pode nos evocar dúvidas acerca da adaptação que pode estreitar os sentidos, enxugando as linhas do texto fonte.

O julgamento de "livro cânone bom" versus "releitura literária ruim" e ainda quanto às adaptações fílmicas, "livro bom" versus "filme ruim" provém da cobrança de fidelidade da segunda obra para com a primeira. A discussão sobre o cânone terá o suporte de Terry Eagleton, em seu provocador estudo sobre Literatura como valor.

\footnotetext{
Um segmento de texto pode começar sua existência como história ou filosofia, e depois passar a ser classificado como literatura; ou pode começar como literatura e passar a ser valorizado por seu significado arqueológico. Alguns nascem literários, outros atingem a condição de literários, e a outros tal condição é imposta Sob esse aspecto, a produção de um texto é muito mais importante do que o seu nascimento. (...) o que importa pode não ser a origem do texto, mas o modo pelo qual as pessoas o consideram... (EAGLETON, 1997, p.12)
}

De acordo com o teórico, portanto, a definição de literatura é um estabelecimento, uma decisão de um grupo mediante aceitação ou recusa majoritária, a despeito do que tenha pensado o seu autor. Em termos de releitura, a definição se expande, propondo mais uma independência: entre a chamada 'original' e a sua 'derivada'.

É preciso, no entanto, analisar as releituras de forma que a exigência de fidelidade para com a obra inspiradora seja questionada, revista, já que a adaptação de um clássico não deve ser uma imitação e nem considerada e/ou valorizada como tal.

A releitura se cria a partir da influência, a respeito afirma Leyla Perrone-Moisés:

Estudando relações entre diferentes literaturas nacionais, autores e obras, a literatura comparada não só admite, mas comprova que a literatura se produz num constante diálogo de textos, por retomadas, empréstimos e trocas. A literatura nasce da literatura: cada obra nova é uma continuação, por consentimento ou contestação, das obras anteriores, dos gêneros e temas já existentes. Escrever é, pois, dialogar com a literatura anterior e com a contemporânea. (PERRONE-MOISÉS, 1990, p.94) 
Assim como os clássicos chegam até nós trazendo marcas de leituras que precederam a nossa, e considerando ainda os traços que deixaram nas culturas que a perpassaram criando e recriando novos sentidos, não é plausível que haja, pois, relação de dívida da releitura em relação à obra inspiradora.

Tal dívida que tratamos aqui seria a obrigatoriedade de integralidade do texto-fonte que não caberia necessariamente no gênero $\mathrm{HQ}$, já que a mesma igualmente desencadeia produção sentido, por novos caminhos e perspectivas introduzindo a literatura em questão ao público que resiste à leitura dos clássicos.

Portanto, à medida que as adaptações em quadrinhos recriam situações, diálogos, personagens, tempo e espaço, transferem todo aquele envolto da trama para o papel, dando ao aluno uma dimensão de como eram aqueles tempos passados de cartolas, vestidos com anáguas, barbichas, penteados e tudo o mais que difere de nossa realidade atual.

É preciso, analisar a releitura como um instrumento didático, e não como o único instrumento a ser utilizado em práticas e leitura. Provocar e instigar este estudante através de gravuras e ilustrações deve ser o principal objetivo ao utilizar uma releitura literária em quadrinhos.

\section{Referências}

AGAMBEN, Giorgio. O que é o contemporâneo e outros ensaios. Chapecó, SC: Argos, 2009.

ALMEIDA, Manuel Antônio de. Memória de Um Sargento de Milícias/ conto de Manuel Antônio de Almeida; roteiro Indigo; arte Bira Danta; cores Maurilio DNA, Caio Freitas. São Paulo: Escala Educacional, 2006. (Série Literatura Brasileira em Quadrinhos)

ASSIS, Machado de. A Cartomante/ conto de Machado de Assis adaptado por Jô Fevereiro e Jô \&CiçaSperl. São Paulo: Escala Educacional, 2007. (Série Literatura Brasileira em Quadrinhos)

ASSIS, Machado de. A Causa Secreta/conto deMachado de Assis, adaptado por Ronaldo Antonelli e Francisco S. Vilachã; cores Fernando A. A. Rodrigues. São Paulo: Escala Educacional, 2007. (Série Literatura Brasileira em Quadrinhos) 
ASSIS, Machado de. O Enfermeiro/conto deMachado de Assis, adaptado por Ronaldo Antonelli e Francisco S. Vilachã; cores Fernando A. A. Rodrigues. São Paulo: Escala Educacional, 2007. (Série Literatura Brasileira em Quadrinhos)

AZEVEDO, Aluísio. O Cortiço/ romance de Aluísio de Azevedo; roteiro e adaptação Ronaldo Antonelli; desenhos Francisco S. Vilachã; cores Fernando A. A. Rodrigues. São Paulo: Escala Educacional, 2007. (Série Literatura Brasileira em Quadrinhos)

BARRETO, Lima. Miss Edith e seu Tio/ Conto de Lima Barreto adaptado por Jô Fevereiro e Jô \&CiçaSperl. São Paulo: Escala Educacional, 2007. (Série Literatura Brasileira em Quadrinhos)

BARRETO, Lima. O Homem que Sabia Javanês/ adaptado por Jô Fevereiro e Sebastião Seabra. São Paulo: Escala Educacional, 2007. (Série Literatura Brasileira em Quadrinhos)

BARRETO, Lima. Um Músico Extraordinário/conto de Lima Barreto, adaptado por Ronaldo Antonelli e Francisco S. Vilachã; cores Fernando A. A. Rodrigues. São Paulo: Escala Educacional, 2007. (Série Literatura Brasileira em Quadrinhos)

BORGES, Taisa. Frankestein em Quadrinhos/ de Mary Shelley/ por Thaisa Borges, tradução Mario Martins de Carvalho. São Paulo: Peirópolis, 2012 (Clássicos em HQ).

BRASIL. Programas do Livro - PLi. Brasília: Ministério da Educação/FNDE, 2004.

Caderno de Estudos do Curso Programas do Livro - PLi/Fundo Nacional de Desenvolvimento da Educação. 5a ed., atual. - Brasília: MEC, FNDE, 2014.

CALVINO, Italo. Por que ler os clássicos. Companhia das Letras. São Paulo: Companhia das Letras, 2007.

COSSON, Rildo. Letramento literário: teoria e prática. São Paulo: Contexto, 2006.

DEFOE, Daniel. Robinson Crusoé/ de Daniel Defoe roteiro, desenho e cor Christophe Gauthier; tradução Luciano Vieira Machado. $2^{a}$ edição, São Paulo: Salamandra, 2009.

LIBÂNEO, José Carlos. Organização e gestão da escola. Goiânia: Alternativa. 2003.

MOON, Fábio. O Alienista/ Machado de Assis: adaptação de Fábio Moon e Gabriel Bá: apresentação de Flávio Moreira da Costa. Rio de Janeiro: Agir, 2007. 
PARRA, Lillo. Sonho de Uma Noite de Verão/ roteiro Lillo Parra; ilustrações de Wanderson de Souza. Belo Horizonte: Editora Nemo, 2011. (Coleção Shakespeare em Quadrinhos)

PINTO, Estêvão. Casa-grande \&Senzala em quadrinhos/ Gilberto Freyre; adaptação Estêvão Pinto; ilustrações de Ivan Wasth Rodrigues; colorização de Noguchi. $2^{a}$ edição, São Paulo: Global, 2005

PERRONE-MOISÉS, Leyla. Literatura comparada, intertexto e antropofagia. In: Flores na escrivaninha. Ensaios. São Paulo: Companhia das Letras, 1990.

QUINTANILHA, Marcello. O Ateneu/ Raul Pompeia; roteiro e arte Marcello Quintanilha. 1 ${ }^{\text {a }}$ edição. São Paulo: Abril Educação, 2013.

ROUANET, Maria Helena. A Terceira Margem do Rio em graphie novell de João Guimarães Rosa, adaptação de Maria Helena Rouanet e Ilustração de Thais dos Anjos - $2^{\mathrm{a}}$ edição. Rio de Janeiro: Ediouro Publicações, 2012.

SHAKESPEARE, Willian. Otelo. Roteiro e desenhos de Jazz; colorista Akira Sanoki. Belo Horizonte: Editora Nemo, 2001 (coleção Shakespeare em Quadrinhos).

SHELLEY, Mary. Frankestein ou O Prometeu moderno; roteiro e desenhos Marion Mousse; cor Marie Galopin; tradução Luciano Vieira Machado. 2a edição - São Paulo: Salamandra, 2009.

STAM, Robert. Introdução à teoria do cinema. Tradução Fernando Mascarello. 2. ed. Campinas: Papirus, 2006.

VETILLO, Walter. O Guarani/ José de Alencar: adaptação Walter Vetillo; Eduardo Vetillo ilustrações. São Paulo: Cortez, 2009. 
